\title{
The recreational value of Lake McKenzie, Fraser Island: An application of the travel cost method
}

\begin{abstract}
Lake McKenzie is one of the most highly used and popular visitor destinations of all Fraser Island's natural sites, attracting 2000 visitors a day in peak periods. Many consider this level of visitation to be unsustainable and the management authority is currently considering a range of management options to address this issue. In assessing the alternatives it is useful to have some idea of the recreational use value of the Lake under the current regime, as it is this value that is at risk if visitor numbers are to be reduced. This paper, using the zonal travel cost method, estimates the recreational use value of Fraser Island and Lake McKenzie for Australian-resident, independent visitors.
\end{abstract}

Key words: Lake McKenzie; Fraser Island; travel cost method; recreation. 


\section{Introduction}

Protected natural areas provide a wide range of benefits to the community. Among the benefits most commonly cited are those associated with the provision of tourism and recreational opportunities, as well as those associated with the provision of ecosystem services. ${ }^{1}$ Unfortunately, trying to maximise both of these benefits can be difficult, and although the consequences of visitor impacts may not be as severe as the impacts of previous human activities in some protected natural areas (e.g. livestock grazing, forestry, and mining), both direct and indirect impacts from recreational use are widespread and are of increasing concern when visitor numbers continue to rise.

This concern has prompted managers of protected natural areas to consider the introduction of various measures to reduce visitor numbers. Such measures include charging entrance fees, making access to sites more difficult (by, for example, restricting vehicle access), demarketing, and the imposition of visitor caps or quotas (Manning, 1999). In evaluating alternative management actions it is necessary to consider all of the benefits and costs of each option. The benefits of reducing visitor numbers are primarily environmental, in that a reduction in the number of visitors is likely to lead to a commensurate reduction in environmental impact. The primary cost, however, is the loss of benefits accruing to visitors now excluded from visiting the site. Thus an appropriate and crucial first step in evaluating the potential impact of policies that seek to impose restrictions on visitor access is to estimate the benefits associated with existing levels of visitation.

This paper, using Lake McKenzie, Fraser Island as a case study, demonstrates that a commonly used non-market valuation technique (the zonal travel cost method) can be used to generate plausible estimates of these benefits. In a contribution to the literature, the method is used to

\footnotetext{
${ }^{1}$ Ecosystem services encompass a range of ecological functions including the purification of air and water, detoxification and decomposition of wastes, regeneration of soil fertility, and production and maintenance of biodiversity (Daily et al., 1997).
} 
estimate the recreational benefits of a 'site within a site'. This issue is particularly relevant because resource managers are often faced with the problem of trying to manage vulnerable, heavily visited recreational sites situated within larger more resilient or less visited protected natural areas. To our knowledge this is the first study to estimate a recreational value for Lake McKenzie, one of Australia’s iconic and vulnerable natural sites.

In Section 2 we introduce the case study, section 3 gives an overview of the travel cost method, including a discussion of some well-known difficulties highlighted in the literature and encountered in this application. Section 4 describes survey methodology and presents key socio-demographic characteristics of respondents. Section 5 gives further details of the modelling process and presents first-stage estimation results. Consumer surpluses are estimated in Section 6. Finally, Section 7 concludes.

\section{Lake McKenzie, Fraser Island}

Situated less than five kilometres off the Queensland coast and some 250 kilometres north of Brisbane, Fraser Island is the largest sand island in the world (166 283 hectares). Inscribed under criteria (vii) and (ix) ${ }^{2}$ on the World Heritage List in 1992, the Island attracts in excess of 300000 visitors per year (Hadwen \& Arthington, 2003). This level of visitation poses considerable environmental threats to the long-term preservation of the Island, with visitors contributing to a range of environmental problems including erosion, litter disposal, human-wildlife interactions ${ }^{3}$ and contamination of the Island's freshwater resources.

\footnotetext{
${ }^{2}$ Criteria (vii): to contain superlative natural phenomena or areas of exceptional natural beauty and aesthetic importance. Criteria (ix): to be outstanding examples representing significant on-going ecological and biological processes in the evolution and development of terrestrial, fresh water, coastal and marine ecosystems and communities of plants and animals (UNESCO, 2007).

${ }^{3}$ Human-dingo interaction in particular has been the focus of much attention over the last decade (see for example, Burns \& Howard (2003)).
} 
A recent report commissioned by the Queensland Environmental Protection Agency (QEPA) highlights the fact that many sites on Fraser Island are being used well beyond their capacity, suggesting that intervention may be required to ensure the Island's long-term sustainability (EDAW, 2002). Further, the Fraser Island World Heritage Area Scientific Advisory Committee recently recommended that visitor management be a priority action in order to minimise resource impacts and optimise the quality of visitor experiences and visitor safety (QEPA, 2002).

Of particular concern is the health of Fraser Island's perched dune lakes, of which there are more than forty, half the number of such lakes in the world. These lakes are formed when organic matter, such as leaves, bark and dead plants gradually build up and harden in depressions created by the wind, creating an impermeable layer. They sit above the regional aquifer and do not typically have inflow or outflow creeks and as such are generally hydrologically closed basins of rainwater. Owing to the fact that rainfall on Fraser Island exceeds water loss via evaporation, very few of the Island's perched dune lakes dry out. In fact Longmore (1997) found that some perched dune lake sediments contain a continuous history (in excess of 300000 years) of the Island's hydrology and vegetation changes, providing an excellent natural archive for paleoenvironmental studies. The lakes are thus a critical component of Australia's natural heritage.

Lake McKenzie is the most highly used and popular visitor destination of all Fraser’s dune lakes, attracting 2000 visitors a day in peak periods (QPWS, 2004). Hadwen, Arthington and Mosich (2003), using a tourist pressure index, rank the Lake as the site most under pressure from tourism on the Island. In response to concerns about over-visitation, the Queensland Parks and Wildlife Service (QPWS) recently closed the lakeside campsite to vehicle-based camping; however self-drive day visitors represent a continuing problem (R. Henderson, personal communication, June 3, 2004). If the Lake's environment continues to degrade, particularly if nutrient levels rise, there is a risk of unsightly and environmentally damaging algal blooms. In this case it may be 
necessary to extend the ban to all vehicle-based visitors, day trippers and campers alike, or in the worst case scenario, to all visitors regardless of access mode.

To gain an appreciation of the potential welfare effects of any move to restrict access to a protected natural area, it is useful to estimate the recreational value or consumer surplus associated with current visitation. While organised tours already face access restrictions to Lake McKenzie, and in the short- to medium-term are unlikely to be restricted further, independent visitors currently face no restrictions and are thus the group most likely to have some form of access restriction imposed upon them in the future. This paper, therefore, using the zonal travel cost method, estimates the current (unrestricted) consumer surplus attributable to visits to Lake McKenzie by independent visitors. This surplus, or at least some portion of it, is most likely to be affected by future management interventions. ${ }^{4}$

It is important to stress that the travel cost method is only capable of estimating the recreational use value of Lake McKenzie; the estimation of non-use values, such as existence, option and bequest values, are beyond the scope of this paper. As such, the estimates presented in Section 6 only represent a fraction of the total value of the Lake. For example, Lee \& Han (2002) using the contingent valuation method to estimate the value of five national parks in South Korea, find that, on average, use values only account for $45.9 \%$ of the parks' total value.

\footnotetext{
${ }^{4}$ It is possible to estimate consumer surplus using a stated preference method, such as contingent valuation. However, the survey instrument used in this study contained questions relating to another stated preference method (choice modelling) investigating visitor preference for alternative management actions. Discussion with practitioners and our own judgement lead us to believe the cognitive burden of answering two sets of stated preference questions was too great. Furthermore, controversy surrounding a previous study (Hundloe, McDonald, Blamey, Wilson, \& Carter, 1990) that attempted to place a monetary value on the preservation of Fraser Island increased our reluctance to use the contingent valuation method. Thus, the travel cost method was deemed the most appropriate non-market valuation technique to employ.
} 


\section{The travel cost method}

\subsection{Introduction}

The travel cost method is a non-market procedure which seeks to place a value on recreational sites by using consumption behaviour in related markets. Specifically, the costs of consuming the recreational amenity of a particular site are used as a proxy for price; these costs can include travel costs, entry fees, on-site expenditures and outlay on capital equipment. The method assumes weak complementarity between the recreational site and consumption expenditure. This implies that when consumption expenditure falls to zero, the marginal utility of visitation is also zero, or alternately the recreational site will only be valued if consumption expenditure is positive (Hanley \& Spash, 1993). The method has become widely accepted and is generally regarded as one of the success stories of non-market valuation (Smith, 1993).

In Australia, Greig's (1973) study of The Grampians in Victoria represents one of the earliest applications of the travel cost method and many subsequent studies have paid particular attention to estimating the recreational values of Australia’s National Parks, with Kakadu (Knapman \& Stanley, 1991), Hinchinbrook Island (Stoeckl, 1995), Girraween (Beal, 1995b), Carnarvon Gorge (Beal, 1995c) and Mount Buffalo (Herath \& Kennedy, 2004) among the recreational sites examined.

There are essentially two types of travel cost models, the individual, where the dependent variable is the number of trips per year (or per season) by individual users of a recreation site, and the zonal, where the dependent variable is the number of trips taken to the site by the population of a particular region or zone. While the former is more appropriate for local, frequently visited, sites, the latter is more appropriate for sites visited infrequently by travellers from afar, and is thus the model employed here.

There are two approaches that may be taken when estimating a zonal travel cost model, the traditional Clawson-Knetsch two-stage methodology (Clawson \& Knetsch, 1966) and the gravity model, often used in geography and transport studies to model commuting decisions. The 
methodology and theoretical underpinnings of these two models are extensively discussed elsewhere (see for example, Hanley \& Spash (1993)) and will not be revisited here. It is sufficient to note that the gravity model produces the same consumer surplus estimates as the more cumbersome Clawson-Knetsch method. In all, the gravity approach is more elegant and has become increasingly popular with practitioners in recent times and is subsequently the approach taken in this paper.

\subsection{Difficulties with the travel cost method}

In practical application, there are a number of difficulties with using the travel cost method. ${ }^{5}$ The three difficulties encountered in this paper are: the treatment of time; the treatment of multiplesite visitors; and the treatment of overseas visitors. These are discussed in turn below.

Since the very earliest applications of the travel cost method (see for example, Cesario (1976) and Cesario \& Knetsch (1970)) the treatment of the cost of time has been problematic. In its essence, the argument for including time costs within the travel cost framework is that, as a scarce commodity, the opportunity cost of time must be included and that failure to do so will increase the price elasticity of demand and therefore reduce the estimated benefits of visiting the recreation site (Freeman, 1993).

Researchers have developed a range of alternative approaches for considering time, including assuming that time can be valued at a fraction (usually between $1 / 4$ and $1 / 2$ ) of the wage rate. There are, however, numerous difficulties with this approach (Bockstael, Strand, \& Hanemann, 1987; Lew \& Larson, 2005; Shaw, 1992). Other approaches include the use of a labour supply model (Feather \& Shaw, 1999) and the use of stated preference data (Alvarez-Farizo, Hanley, \& Barberan, 2001; Casey, Tomislav, \& Danielson, 1995; Larson, Shaikh, \& Layton, 2004; Shaw, 1992). Although the latter approach shows promise, difficulties remain, including the increased cognitive burden

\footnotetext{
${ }^{5}$ A more thorough examination of the difficulties discussed here and others can be found in Freeman (1993).
} 
associated with adding stated preference questions to travel cost surveys. In all there is a strong case for not including time costs at all and this is the approach taken here. This is consistent with that of a number of other practitioners including Siderelis \& Moore (1995), Whitten \& Bennett (2002) and Prayaga, Rolfe \& Sinden (2006) and is also consistent with the findings of Beal (1995a), who in a study seeking to elicit the opportunity cost of travel time for visitors to Girraween and Carnarvon Gorge National Parks in Australia, concludes that it would be inappropriate to include time costs in travel cost valuations.

One of the major assumptions of the travel cost methodology is that only one site is visited per trip. In other words, all the travel costs are incurred exclusively to obtain access to the particular recreation site being valued (Haspel \& Johnson, 1982). If a trip involves visiting multiple sites this assumption is no longer valid. One solution is to apply only a proportion of total travel costs to the site under consideration. This however undermines the basis of the travel cost procedure (Beal, 1995c). The travel cost methodology relies on the tenet that demand falls as prices rise. The correlation between demand and prices disappears when only a fraction of the total costs are used. Another solution is to exclude multiple-site visitors from the sample. Although methodologically reasonable this will have the effect of overestimating per-person benefits whilst underestimating total benefits. ${ }^{6}$ In this paper, the total travel costs of all (multiple- and single-site) visitors are used and the resulting zonal consumer surplus estimates are adjusted according to the average proportion of the total trip that is spent at Fraser Island by visitors from each zone, a method first suggested by Clough \& Meister (1991).

\footnotetext{
${ }^{6}$ We attempted to use both of these methods, namely using only a portion of travel costs and omitting all multiple-site visitors; however, neither yielded satisfactory results. Models using the full sample and adjusted travel costs had poor explanatory power, and in some cases the travel cost variable was not significant at a $10 \%$ level. The exclusion of all multiple-site visitors substantially reduced the number of zones, and thus observations, leading to difficulties with model estimation.
} 
The treatment of overseas visitors can vary (see for example Carr \& Mendelsohn, 2003; Prayaga et al., 2006). The option taken in this paper is to omit all overseas visitors from the sample. When considered from a national perspective, the consumer surplus of overseas visitors is of little interest, except insofar as it can be extracted (through for example, price discrimination or taxation). Thus it is irrelevant to the assessment of the welfare effects of introducing access restrictions. ${ }^{7}$

\section{The Fraser Island survey}

\subsection{Background and survey administration}

Although the objective of this study is to estimate a recreational value of Lake McKenzie, doing so using the travel cost method is problematic because almost all visitors to the Lake also visit other attractions on Fraser Island. In fact Fraser Island itself could be viewed as an attraction and most of the travel costs are spent in reaching the Island. Therefore the recreational value of Fraser Island in its entirety has been estimated and then some of this value is apportioned to Lake McKenzie. How much of the total value allocated to the Lake is determined in this paper by the satisfaction from visiting Lake McKenzie as a proportion of total satisfaction from visiting Fraser Island (as reported by respondents in 2006). ${ }^{8}$

\footnotetext{
${ }^{7}$ Measuring changes in expenditure is a more appropriate method of evaluating the domestic economic impact of restricting overseas visitors' access to a protected natural area. This is beyond the scope of this paper.

${ }^{8}$ An alternative method to apportion value to Lake McKenzie is to use time spent at Lake McKenzie, relative to total time spent on Fraser Island. This approach, however is not considered suitable as vehicle-based visitors do not stay overnight at the Lake and due to road conditions the amount of time that people can hope to spend at Lake McKenzie is generally limited to a few hours; this limitation forces the proportion of time spent at Lake McKenzie to be a small proportion of total time spent on Fraser Island. Moreover, the link between time spent in a recreational activity and the value or enjoyment derived from that activity is tenuous.
} 
Following the method of Wilson \& Tisdell (2004), visitors to Fraser Island were given surveys with pre-paid self-addressed envelopes attached. ${ }^{9}$ This was to give respondents the opportunity to carefully consider replies in their own time. A total of two sampling occasions during 2006 were undertaken, the first in April and the second in August. In April, 800 surveys were distributed over a period of seven days, in August, 560 surveys were distributed over a period of eight days; reflecting the fact that August is a much quieter time of year on Fraser Island. In both cases, surveys were distributed at various locations, predominantly in the lower third of the Island.

As we are interested in the consumer surplus accruing to independent vehicle-based visitors (as this is the group most likely to be affected by any future access restrictions), only these visitors, and not those on commercial tours, were surveyed.

Of relevance to this paper, in addition to questions asking the respondents' home town and from where they departed the mainland to travel to Fraser Island, was a question seeking to obtain information from which travel costs could be estimated (reproduced in Box 1). ${ }^{10}$

\section{[INSERT BOX 1]}

\subsection{Socio-demographic characteristics of respondents}

Out of the 1360 surveys distributed over both sampling periods, a total of 463 surveys were returned, of which 430 were useable, giving a response rate of 31.6\%. Of these, 349 (75\%) respondents were Australian residents and thus used in this study. Figure 1 illustrates that the majority of respondents (70\%) are from Queensland, with the remainder from New South Wales

\footnotetext{
${ }^{9}$ A copy of the survey is available on request.

${ }^{10}$ Due to the wide range of potential methods of travelling, and routes, to Fraser Island, the open-ended format was deemed the most appropriate means of obtaining information on travel behaviour and therefore costs. In all, this question was well-answered by respondents and we would recommend practitioners consider this approach in the future.
} 
(17\%), Victoria (9\%), South Australia (3\%) and Western Australia (1\%). There were no respondents from the Australian Capital Territory, Tasmania or the Northern Territory.

\section{[INSERT FIGURE 1]}

Summary statistics of respondents are presented in Table 1 . The mean age of respondents is approximately 41, which is older than the average age (37 years) of the wider Australian population (ABS, 2007a). The sample is highly educated, with almost half of respondents reporting that they have a bachelor degree or above (compared with only $18.4 \%$ of the Australian adult population (ABS, 2006)). Respondents were comparatively wealthy, reporting a mean weekly household income of approximately $\$ 1500,{ }^{11}$ compared to an Australia-wide mean of $\$ 1027$. Further, 31\% of respondents report a weekly household income in excess of \$2 000, compared to only 18\% of households Australia-wide (see Figure 2) (ABS, 2007b).

[INSERT TABLE 1]

[INSERT FIGURE 2]

\section{Application of the travel cost method}

\subsection{Definition of the dependent variable}

The dependent variable for a zonal travel cost analysis is the rate of visitation from each of a number of researcher determined zones to the study site. In the Australian context, zones have often been based on Statistical Divisions ${ }^{12}$ (Cook \& Harrison, 2002; Prayaga et al., 2006; Stoeckl, 1995; Ward \& Beal, 2000) and this is the approach taken here. In all, the sample included observations

\footnotetext{
${ }^{11}$ All figures are in AU \$. AU \$ = 0.8140 US \$; 0.4130 UK £ (9 September 2007).

${ }^{12}$ A Statistical Division is a defined area which represents large, general purpose, regional type geographic areas. It represents a relatively homogeneous region characterised by identifiable social and economic links between the inhabitants and between the economic units within the region. They cover, in aggregate, the whole of Australia without gaps or overlaps. They do not cross State or Territory boundaries (ABS, 2003).
} 
from 25 different Statistical Divisions, and thus 25 observations are used in the first-stage estimation.

It was decided to calculate separate visitation rates for each zone for the April and August samples, and then use a weighted average to obtain an annual zonal visitation rate. Thus, for April (denoted subscript 1 ) the visitation rate (per 10 000) for zone $i$ is given by:

$$
V R_{1, i}=\frac{V_{1, i}}{N_{i} \times 0.04027}
$$

and for August (denoted subscript 2) by:

$$
V R_{2, i}=\frac{V_{2, i}}{N_{i} \times 0.04903}
$$

where, $V_{1, i}$ is the number of adult visitors sampled in April from zone $i, V_{2, i}$ is the number of adult visitors sampled in August from zone $i, N_{i}$ is the population of zone $i$ aged 15 years and over (in units of 10 000) and 0.04027 and 0.04903 are the sampling fractions for April and August respectively. ${ }^{13}$

The annual zonal visitation rates are calculated using a weighted average of the monthly rates calculated above. The April rate, representing a peak visitation month, is given a weighting of $1 / 3^{\text {rd }}$ reflecting the fact that 4 of 12 months (January, April, September and December) are regarded as peak visitation months, the August rate, representing an off-peak visitation month is therefore given a weighting of $2 / 3^{\text {rds }}$. The formula is:

$$
V R_{i}=\frac{1}{3} \times V R_{1, i}+\frac{2}{3} \times V R_{2, i}
$$

where $V R_{i}$ is the annual visitation rate of zone $i$ and all other variables are as previously defined.

\footnotetext{
${ }^{13}$ The sampling fraction is the ratio of the number of parties in the sample to the annual number of permits issued to Australians, and thus scales the visitation rate to be applicable to the population.
} 


\subsection{Definition of travel costs}

Total travel costs are initially calculated per 'party' and include (where applicable): vehicle costs; air, bus and rail fares; recreational areas management (RAM) vehicle access permit fees; and barge fees. These costs are considered in more detail below. Per-person travel costs are then estimated by dividing 'party' travel costs by the number of adults in the party. ${ }^{14}$ Per-person travel costs are therefore calculated using:

$$
\text { TC per person }=\frac{\text { Vehicle Costs }+ \text { Air Fares }+ \text { Bus Fares }+ \text { Rail Fares }+ \text { RAM Fee }+ \text { Barge Fee }}{\text { Number of Adults in the Party }}
$$

In regard to vehicle costs, respondents were asked to indicate the approximate size of vehicle in which they traveled. Seven size categories were suggested, corresponding to categories in the 2006 National Roads and Motorists’ Association (NRMA) Private Motoring Cost Schedule. The NRMA vehicle costs are calculated using an average price of $137.5 \mathrm{c}$ per litre ${ }^{15}$ for unleaded petrol and include capital costs (depreciation, costs of funds), fixed costs (registration, compulsory third party insurance, comprehensive vehicle insurance, NRMA membership) and operating costs (fuel, tyres, service \& repairs) (NRMA, 2006). A 10\% operating cost premium was added for those respondents who indicated that they were towing a trailer. These costs are presented in Table 2.

\section{[INSERT TABLE 2]}

The vehicle cost included in the travel cost variable was obtained as the product of the NRMA operating cost and the road distance traveled. Road distances are calculated using the Royal Automobile Club of Queensland (RACQ) Trip Planner (RACQ, 2006), with points of departure and

\footnotetext{
${ }^{14}$ It is assumed children 15 years and over do not contribute to paying costs and therefore represent an additional cost burden to the adults in the party.

${ }^{15}$ This is a relatively high fuel price, reflecting the fact that New South Wales, where the NRMA calculations are derived, has a higher level of taxation on fuel than Queensland.
} 
arrival entered as postcodes. The trip planner calculates the shortest, not always the most scenic, route and distance calculations should therefore be viewed as conservative. ${ }^{16}$

Air fares, bus and rail fares are calculated using the respective appropriate websites (Flight Centre, 2006; Greyhound Australia, 2006; Travel Train, 2006). In each case it is assumed the fare is for the economy class booked four weeks in advance. These costs should therefore be viewed as conservative.

Before bringing a vehicle onto Fraser Island, visitors must obtain a RAM vehicle access permit. The fee for this permit (valid for one month) at the time of the survey was $\$ 33.45$ (per vehicle). An annual permit is also available for a fee of $\$ 172.30$. It is assumed all parties bringing a vehicle onto the Island had purchased a one month RAM vehicle access permit.

There are a number of barges operating between the mainland and Fraser Island. Those departing from the southern end of the Island can travel on the Manta Ray, Rainbow Venture or Fraser Explorer, those accessing the western side of the Island can travel on the Fraser Venture, Kingfisher Bay Barge, Fraser Dawn or Kingfisher Bay Fastcat. Respondents were not asked to indicate which barge they traveled on, they were, however, asked to state a departure point from the mainland and this is used to determine an approximate barge fee. In all cases it is assumed a return ticket was purchased.

\subsection{Definition of socio-economic variables}

The survey asked respondents to identify their age, highest level of educational attainment and household income. The age question presented respondents with a series of age brackets at ten-year intervals. In order to calculate the average age of respondents from each zone, the age of each respondent was assumed to be equal to the mid-point of each bracket.

\footnotetext{
${ }^{16}$ Liston-Heyes (1999) demonstrates that the use of such a planner generates travel time and distance estimates that are consistent with those directly reported by travellers.
} 
Four education categories were defined, coded as 1 to 4 , where 1 represented having completed less than Year 12 (final year of schooling) or equivalent, and 4 represented having at least a bachelor degree. From this information the average educational attainment of respondents from each zone is calculated.

As with the age question, respondents were asked to indicate their before-tax household income by selecting a particular income bracket. Mid-points were again used to determine the average household income of respondents from each zone.

\subsection{Model selection}

To obtain the trip generating function, the zonal visitation rate was regressed against average zonal travel cost (TC) and the three socio-demographic variables (age, education, income). As is typical with zonal travel cost studies (see for example, Beal, 1995c; Nillesen, Wesseler, \& Cook, 2005) none of the socio-demographic variables were found to be significant, even at the $10 \%$ level so these were removed from further analysis. As there is no theoretical reason for choosing one functional form over another, linear, linear-log, log-linear and log-log equations were all estimated. Observation of scatter diagrams, log likelihood values, the adjusted $\mathrm{R}^{2}$, F-statistics and Schwarz and Akaike information criterion values as reported in Table 3 were all considered in choosing the best functional form. Following Chotikapanich \& Griffiths’ (1998) suggestion that the value of the maximised log likelihood function is preferable to $\mathrm{R}^{2}$ as a descriptive goodness of fit measure, particularly for models with different dependent variables, log-likelihood values were used as a primary means of determining the functional form that best fits the data. Against all criteria, the functional form of the preferred equation was found to be $\operatorname{Ln}(V R)=\beta_{0}+\beta_{1} \operatorname{Ln}(T C)$. Thus the log-log model was chosen for further analysis.

[INSERT TABLE 3] 
Inserting current average zonal travel cost and multiplying by zonal population, this model yields an estimated number of annual visits of 130 909. Given there are approximately 300000 visitors annually, and the model estimates only Australian residents traveling independently, this figure seems reasonable. Further, if this level of visitation is divided by the annual number of vehicle permits estimated to be issued to Australian residents (38 775), an average of 3.4 adults per vehicle is obtained, which is also a reasonable estimate given the average number of adults per vehicle in the sample was 3.6.

\section{Consumer surplus estimation}

\subsection{Estimates for Fraser Island}

With the assumption that people will respond to increases in price in a similar way to increases in travel cost, the visitation levels corresponding to a schedule of travel costs was derived. In theory this involves incrementing the travel cost variable until zero visitation is obtained, thus identifying the choke price for each zone. However, due to the nature of a logarithmic function, it is not possible to obtain a zero level of visitation. Instead choke prices were identified at that point where the level of visitation in each zone reached one. For each zone the level of visitation $V_{i}$ was calculated using two equations:

$$
\begin{aligned}
& \operatorname{Ln}(\mathrm{VR})=11.22568-1.067552 \ln (\mathrm{TC}) \\
& \mathrm{V}_{\mathrm{i}}=\mathrm{VR}_{\mathrm{i}} \times \frac{\mathrm{N}_{\mathrm{i}}}{10,000}
\end{aligned}
$$

where $V R_{i}$ is the weighted average visitation rate as defined in equation (3), and $V_{i}$ represents the scaled number of visits per 10000 population from each zone for the year.

Hence,

$$
\mathrm{V}_{\mathrm{i}}=\frac{\mathrm{N}_{\mathrm{i}}}{10,000} \mathrm{e}^{11.22568} \times \mathrm{TC}^{-1.067552}
$$


The trip generating function was integrated for each zone between the actual travel cost and the zonal choke price travel cost. This estimates consumer surplus for each zone.

Consumer surplus is thus,

$$
\begin{aligned}
\mathrm{CS}_{\mathrm{i}} & =\frac{\mathrm{N}_{\mathrm{i}}}{10,000} \mathrm{e}^{11.22568} \int_{\mathrm{TC}_{\mathrm{i}}}^{\mathrm{TC}_{\mathrm{i}}+\Delta \mathrm{C}_{\max }} \mathrm{TC}^{-1.067552} \mathrm{dTC} \\
= & \frac{N_{i}}{10,000} e^{11.22568} \times\left[\frac{T C^{-0.067552}}{-0.067552}\right]_{T C_{i}}^{T C_{i}+\Delta C_{\max }}
\end{aligned}
$$

All the zonal answers were added to obtain the estimate of total consumer surplus. This yielded a surplus of approximately $\$ 417.5$ million per annum, which converts to \$3 189 per-person pervisit. Following the methodology of Chotikapanich \& Griffiths (1998), in order to gain an indication of the reliability of this consumer surplus estimate, the approximate standard error and consequent confidence interval were obtained using the asymptotic variance, given by:

$$
\operatorname{var}(\hat{C} S)=\left(\frac{\partial(C S)}{\partial \beta_{0}}\right)^{2} \operatorname{var}\left(\hat{\beta}_{0}\right)+\left(\frac{\partial(C S)}{\partial \beta_{1}}\right)^{2} \operatorname{var}\left(\hat{\beta}_{1}\right)+2\left(\frac{\partial(C S)}{\partial \beta_{0}}\right)\left(\frac{\partial(C S)}{\partial \beta_{1}}\right) \operatorname{cov}\left(\hat{\beta}_{0}, \hat{\beta}_{1}\right)
$$

This value along with the estimated consumer surplus is used to calculate a 95\% confidence interval of \$251.5 to \$583.5 million per annum, or \$1 921 to \$4 475 per-person per-visit. This relatively wide confidence interval shows there is a high degree of uncertainty associated with our consumer surplus estimate, a result consistent with other studies in the literature (see for example Chotikapanich \& Griffiths, 1998; Lansdell \& Gangadharan, 2003).

To account for multiple-site visitors, each zonal estimate of consumer surplus was adjusted according to the average zonal proportion of time spent on Fraser Island, relative to the time spent away from home on the trip, as given by equation (11).

$$
\text { Proportion of consumer surplus allocated to Fraser Island }=\frac{N I_{X}}{T N_{x}}
$$


where $N I_{x}$ is the number of nights spent on Fraser Island by visitor $x$ and $T N_{x}$ is the total number of nights spent away from home by visitor $x$. If this proportion is equal to 1 , or if $T N_{x}$ is zero (signifying a day trip), then $100 \%$ of the consumer surplus is allocated to the Island. This yields an adjusted consumer surplus of \$191.4 million, which converts to \$1 462 per-person pervisit. Assuming the relative contribution of each zone to total consumer surplus at the lower and upper bounds is the same as at the point estimate, $95 \%$ confidence intervals of the adjusted consumer surplus can be calculated. These are \$115.3 to \$267.4 million per annum, or \$881 to \$2 043 per-person per-visit.

\subsection{Estimates for Lake McKenzie}

The above consumer surplus values are the estimates for Fraser Island as a whole. Once on Fraser Island visitors undertake different activities and visit various sites. In order to gauge the level of utility or satisfaction gained from visiting Lake McKenzie (and thus to determine what proportion of consumer surplus may be attributed to the Lake), respondents were asked a question regarding their enjoyment of their visit to the Lake, as a proportion of their total enjoyment of their visit to Fraser Island (reproduced in Box 2). ${ }^{17}$,

\section{[INSERT BOX 2]}

To estimate a consumer surplus for Lake McKenzie, the average zonal reported satisfaction measure (which ranged from 0 to 35\%, with an average of 15.6\%) is multiplied by the estimated zonal consumer surplus, and then all adjusted surpluses are summed. This, using the consumer surplus estimates adjusted for multiple-site visitors, yields an estimate for Lake McKenzie of \$31.8

\footnotetext{
${ }^{17}$ In an earlier pilot, a more complete list of possible attractions of Fraser Island were listed, with respondents asked to attribute a proportion of enjoyment to each. However, this question was poorly answered and left blank by many respondents and was thus replaced with the question in Box 2.
} 
million, or an average of $\$ 243$ per-person per-visit (confidence intervals of $\$ 19.2$ to $\$ 44.4$ million per annum, or \$146 to \$339 per-person per-visit).

\subsection{Summary}

As presented in Table 4, this application of the travel cost method has produced a range of estimates for both Fraser Island and Lake McKenzie. Due to the issue of multiple-site visitation discussed in Section 2.1, the unadjusted estimates reported in the left hand columns are not considered reasonable. As an example of the difficulty with using unadjusted estimates, consider the case of one respondent who had travelled to Fraser Island from Adelaide (a distance of some $2200 \mathrm{~km}$ ) and spent three nights of a 28 night trip on the Island. Under the unadjusted calculation, the total travel cost of the entire trip is allocated to the value of Fraser Island, a patently absurd outcome.

\section{[INSERT TABLE 4]}

Therefore considering the adjusted estimates only, the annual recreational value of Fraser Island for Australian-resident, independent visitors, is substantial, ranging with 95\% confidence between approximately \$115.3 and \$267.4 million per annum. For Lake McKenzie these estimates range from \$19.2 to \$44.4 million per annum. Given that the analysis presented here does not measure the recreational value to those on organised tours, nor does it measure non-use values, the total economic value of Fraser Island and Lake McKenzie is likely to be a much higher figure than those reported here.

While the inherently unique nature of protected natural areas makes it difficult to compare these results with those of other studies, Carr \& Mendelsohn’s (2003) valuation of the Great Barrier Reef, which found a consumer surplus for Australian visitors of around US \$400 million per annum (AU \$600 million in 2006 dollars) is a useful point of comparison. This figure, approximately three 
times the annual estimate of \$191.4 million for Fraser Island, gives some indication that the estimates found in this paper are within a plausible range.

\section{Conclusion}

Managing a World Heritage Area is a difficult task, management has an obligation to preserve the area for future generations, as well as allow access for the present generation. In this context, the QPWS, who are charged with managing Fraser Island, need to try and accommodate an everincreasing number of tourists while preserving the very qualities that tourists (and others) value. Of all the sites on the Island, Lake McKenzie is the most under pressure from tourism, and therefore is the site in most need of some form of management intervention.

In order to assess the relative merits of alternative management strategies it is useful to be able to weigh the benefits and costs of each option; a logical first step in this process is to estimate the recreational value associated with current visitation. The estimates found in this paper confirm that there is a substantial current recreational value for both Fraser Island and Lake McKenzie and caution, therefore, is needed before moving to restrict access to this publicly owned recreational site. That is not to suggest the imposition of access restrictions is necessarily a poor policy per se, simply that this potential loss of welfare needs to be balanced against any potential gains in value (including in non-use value) resulting from reduced visitor numbers.

The next step in the evaluation process is to investigate alternative measures to reduce visitor numbers, consider the likely impact of these measures on total visitation, and use the estimates reported in this paper to assess the cost (in terms of reduced consumer surplus) of imposing each measure. This cost needs to be evaluated against the expected benefits of imposing restrictions on visitor access. If, within a benefit-cost framework it can be demonstrated that the present value of these benefits outweigh the present value of the costs, policies to reduce visitor access can be defended on economic efficiency grounds. 


\section{References}

ABS. (2003). Glossary of Statistical Geography Terminology. Canberra.

ABS. (2006). Survey of Education and Training, Australia, 2005. Canberra.

ABS. (2007a). 2006 Census of Population and Housing: Age by Sex. Canberra.

ABS. (2007b). 2006 Census of Population and Housing: Gross Household Income (Weekly) By Household Composition. Canberra.

Alvarez-Farizo, B., Hanley, N., \& Barberan, R. (2001). The value of leisure time: A contingent rating approach. Journal of Environmental Planning and Management, 44(5), 681-699.

Beal, D. (1995a). The cost of time in travel cost analyses of demand for recreational use of natural areas. Australian Journal of Leisure and Recreation, 5(1), 9-13.

Beal, D. (1995b). Estimation of the elasticity of demand for camping visits to a national park in south-east Queensland. Australian Leisure, 7(1), 21-26.

Beal, D. (1995c). A travel cost analysis of the value of Carnarvon Gorge National Park for recreational use. Review of Marketing and Agricultural Economics, 63(2), 292-303.

Bockstael, N., Strand, I., \& Hanemann, W. M. (1987). Time and the recreational demand model. American Journal of Agricultural Economics, 69(2), 293-302.

Burns, G., \& Howard, P. (2003). When wildlife tourism goes wrong: A case study of stakeholder and management issues regarding Dingoes on Fraser Island, Australia. Tourism Management, 24(6), 699-712.

Carr, L., \& Mendelsohn, R. (2003). Valuing coral reefs: A travel cost analysis of the Great Barrier Reef. Ambio, 32(5), 353-357.

Casey, J., Tomislav, V., \& Danielson, L. (1995). The economic value of hiking: Further considerations of opportunity cost of time in recreation demand models. Journal of Agriculture and Applied Economics, 27(2), 658-668. 
Cesario, F. (1976). Value of time in recreation benefit studies. Land Economics, 52(1), 32-41.

Cesario, F., \& Knetsch, J. (1970). Time bias in recreation benefit studies. Water Resources Research, 6(3), 700-704.

Chotikapanich, D., \& Griffiths, W. (1998). Carnarvon Gorge: A comment on the sensitivity of consumer surplus estimation. Australian Journal of Agricultural and Resource Economics, 42(3), 249-261.

Clawson, M., \& Knetsch, J. (1966). Economics of Outdoor Recreation. Baltimore: John Hopkins University Press.

Clough, P., \& Meister, A. (1991). Allowing for multiple-site visitors in travel cost analysis. Journal of Environmental Management, 32(2), 115-125.

Cook, A., \& Harrison, S. (2002). Economic evaluation of proposed long-distance walking tracks in the Wet Tropics of Queensland. Economic Analysis and Policy, 32(2), 113-129.

Daily, G., Alexander, S., Ehrlich, P., Goulder, L., Lubchenco, J., Matson, P., et al. (1997). Ecosystem services: Benefits supplied to human societies by natural ecosystems. Issues in Ecology, 2(1), 1-18.

EDAW. (2002). Fraser Island desired site capacities study: Final report. Brisbane: Queensland Environmental Protection Agency.

Feather, P., \& Shaw, W. D. (1999). Estimating the cost of leisure time for recreation demand models. Journal of Environmental Economics and Management, 38(1), 49-65.

Flight Centre. (2006). Retrieved 7 October, from http://www.flightcentre.com.au/

Freeman, A. M. (1993). The Measurement of Environmental and Resource Values: Theory and Methods. Washington DC: Resources for the Future. 
Greig, P. (1973). The Management Decision-Making Process in the Mulitple Use of Forested Lands, with Particular Reference to Outdoor Recreation. Unpublished Master of Science thesis, University of Melbourne, Melbourne.

Greyhound Australia. (2006). Retrieved 7 October, from www.greyhound.com.au/default.aspx

Hadwen, W., \& Arthington, A. (2003). The significance and management implications of perched dune lakes as swimming and recreation sites on Fraser Island, Australia. Journal of Tourism Studies, 14(2), 35-44.

Hadwen, W., Arthington, A., \& Mosisch, T. (2003). The impact of tourism on dune lakes on Fraser Island, Australia. Lakes and Reservoirs: Research and Management, 8(1), 15-26.

Hanley, N., \& Spash, C. (1993). Cost-Benefit Analysis and the Environment. Aldershot: Edward Elgar.

Haspel, A., \& Johnson, F. R. (1982). Multiple destination trip bias in recreation benefit estimation. Land Economics, 58(3), 364-372.

Herath, G., \& Kennedy, J. (2004). Estimating the economic value of Mount Buffalo National Park with the travel cost and contingent valuation models. Tourism Economics, 10(1), 63-78.

Hundloe, T., McDonald, G., Blamey, R., Wilson, B., \& Carter, M. (1990). Socio-economic analysis of non-extractive natural resource uses in the Great Sandy Region. Brisbane: Griffith University.

Knapman, B., \& Stanley, O. (1991). A travel cost analysis of the recreation use value of Kakadu National Park. Canberra: Resource Assessment Commission.

Lansdell, N., \& Gangadharan, L. (2003). Comparing travel cost models and the precision of their consumer surplus estimates: Albert Park and Maroondah Reservoir. Australian Economic Papers, 42(4), 399-417. 
Larson, D., Shaikh, S., \& Layton, D. (2004). Revealing preferences for leisure time from stated preference data. American Journal of Agricultural Economics, 86(2), 307-320.

Lee, C.-K., \& Han, S.-Y. (2002). Estimating the use and preservation values of national parks' tourism resources using a contingent valuation method. Tourism Management, 23(5), 531-540.

Lew, D., \& Larson, D. (2005). Accounting for stochastic shadow values of time in discrete-choice recreation demand models. Journal of Environmental Economics and Management, 50(2), 341361.

Liston-Heyes, C. (1999). Stated vs. computed travel data: A note for TCM practitioners. Tourism Management, 20(1), 149-152.

Longmore, M. (1997). Quaternary palynological records from perched lake sediments, Fraser Island, Queensland, Australia: Rainforest, forest history and climatic control. Australian Journal of Botany, 45(3), 507-526.

Manning, R. (1999). Studies in Outdoor Recreation: Search and Research for Satisfaction (second ed.). Corvallis: Oregon State University Press.

Nillesen, E., Wesseler, J., \& Cook, A. (2005). Estimating the recreational-use value for hiking in Bellenden Ker National Park, Australia. Environmental Management, 36(2), 311-316.

NRMA. (2006). Private Motoring Cost Schedule June 2006. Retrieved 5 October 2006, from www.mynrma.com.au/operating_costs.asp

Prayaga, P., Rolfe, J., \& Sinden, J. (2006). A travel cost analysis of the value of special events: Gemfest in Central Queensland. Tourism Economics, 12(3), 403-420.

QEPA. (2002). Australian National Periodic Report: Section II, Report on the State of Conservation of Fraser Island. Brisbane.

QPWS. (2004). New Fraser campground helps sustain island environment. Brisbane. 
RACQ. (2006). Trip Planner. Retrieved 5 October, from

http://www.racq.com.au/cps/rde/xchg/racq_cms_production/hs.xsl/trip_planner_ENA_HTML.h $\underline{\operatorname{tm}}$

Shaw, W. D. (1992). Searching for the opportunity cost of an individual's time. Land Economics, 68(1), 107-115.

Siderelis, C., \& Moore, R. (1995). Outdoor recreation net-benefit of rail trails. Journal of Leisure Research, 27(4), 344-359.

Smith, V. K. (1993). Nonmarket valuation of environmental resources: An interpretive appraisal. Land Economics, 69(1), 1-26.

Stoeckl, N. (1995). A travel cost analysis of Hinchinbrook Island National Park. In B. Faulkner, M. Fagence, M. Davidson \& S. Craig-Smith (Eds.), Tourism Research and Education in Australia (proceedings of the Australian National Tourism Research and Education Conference, Gold Coast, 1994) (pp. 187-201). Canberra: Bureau of Tourism Research.

Travel Train. (2006). Retrieved 7 October, from http://www.traveltrain.com.au/

UNESCO. (2007). Fraser Island - UNESCO World Heritage Centre. Retrieved 8 March 2007, from http://whc.unesco.org/en/list/630

Ward, F., \& Beal, D. (2000). Valuing Nature with Travel Cost Models: A Manual. Cheltenham: Edward Elgar.

Whitten, S., \& Bennett, J. (2002). A travel cost study of duck hunting in the Upper South East of South Australia. Australian Geographer, 33(2), 207-221.

Wilson, C., \& Tisdell, C. (2004). Attitudes to entry fees to National Parks: Results and policy implications from a Queensland case study. Economic Analysis and Policy, 34(1), 79-102. 
Table 1: Gender, mean age, income and education of respondents

\begin{tabular}{lc}
\hline Variable $^{\mathrm{a}}$ & \\
\hline Gender - proportion of sample male $^{\mathrm{b}}$ & $54 \%$ \\
Mean age $^{\mathrm{b}}$ - years & 40.9 \\
& $(13.2)$ \\
Mean highest educational attainment & \\
& 3.2 \\
Mean income - gross weekly household AU \$ & $(0.9)$ \\
& $\$ 1524$
\end{tabular}

a Standard deviation reported in brackets.

b Categories used were: 0-19, 20-29, 30-39, 40-49, 50-59, 60-69, 70-79 \& 80+. Mean response values were calculated from the mid-points of category values. No respondent selected the $80+$ category.

c Categories used were: completed less than year 12 (highest year of schooling) or equivalent (coded 1), completed year 12 or equivalent (coded 2), trade certificate or equivalent (coded 3) and Bachelor or higher degree or equivalent (coded 4).

d Categories used were: $<\$ 200$, \$200-399, \$400-599, \$600-799, \$800-999, \$1 000-1 199, \$1 200-1 399, \$1 400-1 599, \$1 600-1 799, \$1 800-1 999 \& \$2 000+. Mean response values were calculated from the mid-points of category value. For those who selected the highest category ( $\$ 2000+$ ) a figure of $\$ 2500$ was used. 
Table 2: Vehicle operating costs

\begin{tabular}{lc}
\hline Vehicle size & $\begin{array}{c}\text { Average operating cost } \\
\text { (cents/km) }\end{array}$ \\
\hline Light car & 46.29 \\
Small car & 57.01 \\
Medium car & 73.53 \\
Large car & 89.46 \\
Compact SUV & 74.06 \\
Medium SUV & 96.39 \\
Large SUV & 103.97 \\
\hline
\end{tabular}


Table 3: First-stage estimation equations

\begin{tabular}{lrrrr}
\hline & Linear & Linear-Log & Log-Linear & Log-Log \\
\hline$\beta_{0}$ & 246.102 & 1034.422 & 5.412 & 11.226 \\
& $(6.523)$ & $(8.844)$ & $(26.772)$ & $(17.172)$ \\
$\beta_{1}$ & -0.140 & -140.492 & -0.001 & -1.068 \\
& $(-4.040)$ & $(-7.865)$ & $(-6.801)$ & $(-10.693)$ \\
adjR ${ }^{2}$ & 0.390 & 0.717 & 0.653 & 0.833 \\
Log likelihood & -151.828 & -142.213 & -21.097 & -12.539 \\
Durbin-Watson & 2.277 & 2.214 & 2.452 & 2.182 \\
Akaike information criterion & 12.306 & 11.537 & 1.848 & 1.163 \\
Schwarz criterion & 12.403 & 11.635 & 1.945 & 1.261 \\
F-statistic (p-value) & 16.322 & 61.857 & 46.260 & 114.342 \\
& $(0.001)$ & $(0.000)$ & $(0.000)$ & $(0.000)$ \\
\hline
\end{tabular}


Table 4: Summary of consumer surplus point and interval estimates (AU \$)

\begin{tabular}{|c|c|c|c|c|c|c|}
\hline & \multicolumn{3}{|c|}{ Full sample unadjusted } & \multicolumn{3}{|c|}{ Adjusted for multiple-site visitors } \\
\hline & \multirow[t]{2}{*}{ Point estimate } & \multicolumn{2}{|c|}{$95 \%$ interval estimates } & \multirow{2}{*}{ Point estimate } & \multicolumn{2}{|c|}{$95 \%$ interval estimates } \\
\hline $\begin{array}{l}\text { Fraser } \\
\text { Island }\end{array}$ & & Lower & Upper & & Lower & Upper \\
\hline $\begin{array}{l}\text { Total } \\
\text { (per } \\
\text { annum) }\end{array}$ & 417494101 & 251508979 & 583479224 & 191353287 & 115276047 & 267430526 \\
\hline $\begin{array}{l}\text { Per- } \\
\text { person } \\
\text { per- } \\
\text { visit }\end{array}$ & 3189.20 & 1921.26 & 4475.15 & 1461.73 & 880.58 & 2042.87 \\
\hline \multicolumn{7}{|l|}{$\begin{array}{l}\text { Lake } \\
\text { McKenzie }\end{array}$} \\
\hline $\begin{array}{l}\text { Total } \\
\text { (per } \\
\text { annum) }\end{array}$ & 75713369 & 45611644 & 105815095 & 31789212 & 19150623 & 44427801 \\
\hline $\begin{array}{l}\text { Per- } \\
\text { person } \\
\text { per- } \\
\text { visit }\end{array}$ & 578.37 & 348.42 & 808.31 & 242.84 & 146.29 & 339.38 \\
\hline
\end{tabular}


Figure 1: Distribution of respondents by state

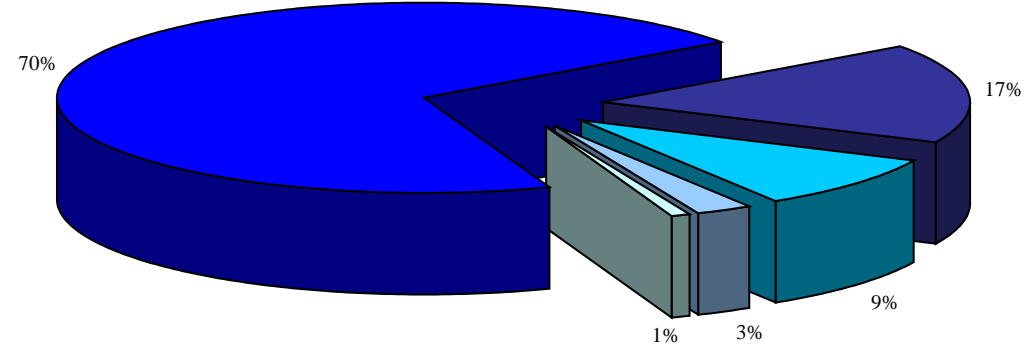

$\square$ Queensland

$\square$ New South Wales

$\square$ Victoria

$\square$ South Australia

$\square$ Western Australia 
Figure 2: Distribution of visitors by income

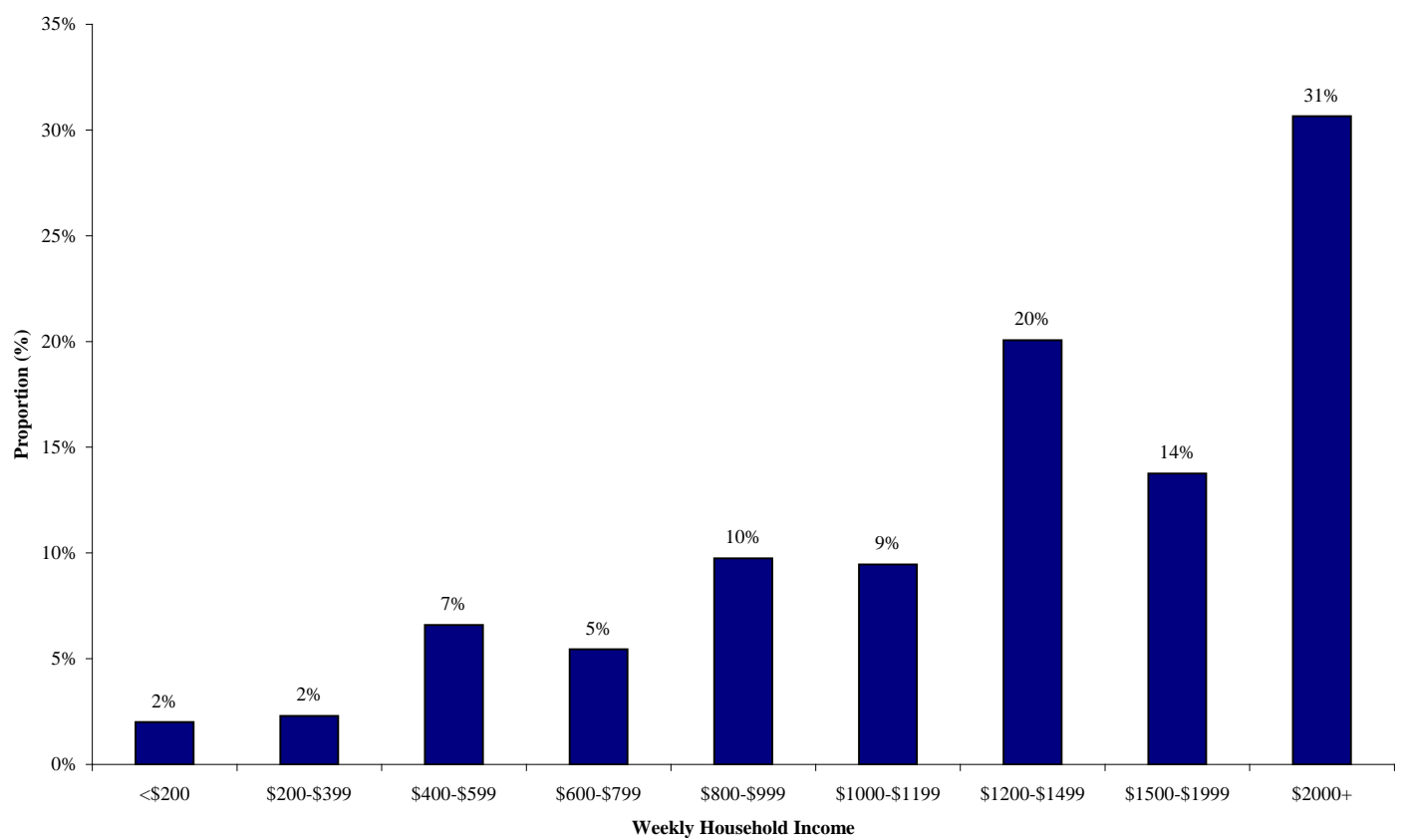


Box 1: The travel cost question

\section{Question 7:}

Briefly describe how you travelled from your home to the departure point given in Question 6 above. If you travelled by car or $4 \mathrm{wd}$ please indicate the approximate size of the vehicle i.e. light car (Toyota Echo or similar), small car (Toyota Corolla or similar), medium car (Mazda 6 or similar), large car (Ford Falcon or similar), compact 4wd (Ford Escape or similar) medium 4wd (Nissan Pathfinder or similar) or large 4wd (Toyota Landcruiser or similar) and whether it was privately owned or rented.

For example:

1 flew from sydney to Brisbane and then drove a medium sized rental car from Brisbane to inskip Point.

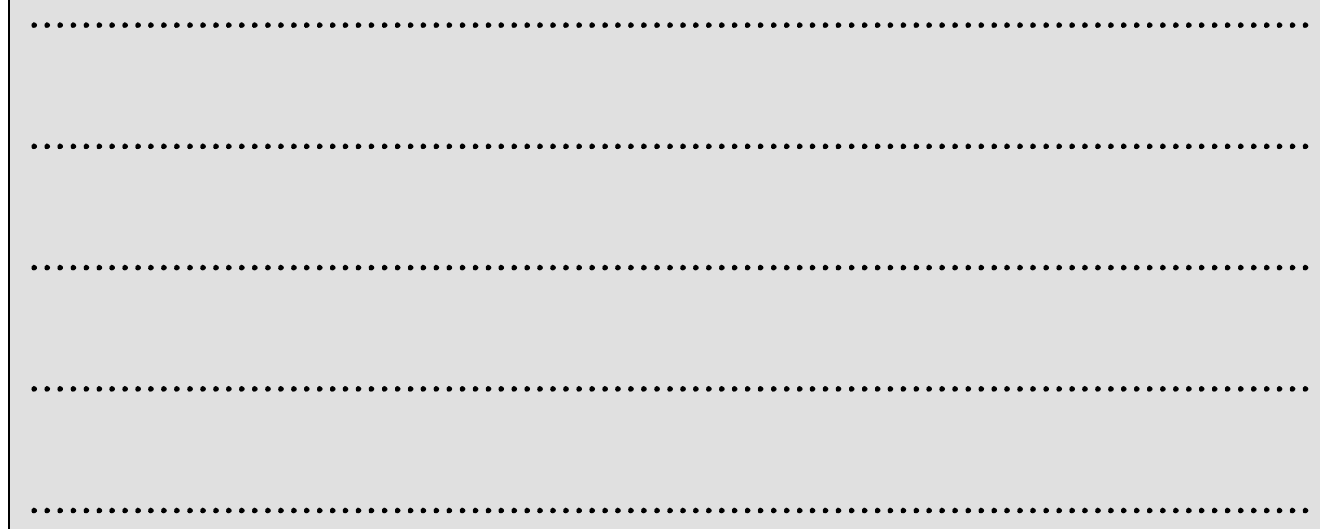


Box 2: The enjoyment question

Question 12:

Of the total enjoyment from your visit to Fraser Island, what proportion would you attribute to the time spent at Lake McKenzie (for example, 5\%, 15\% etc.) ?................................................ \% 